\title{
A New Variant of Galactosemia: Galactose-1- phosphate Uridylytransferase Sensitive to Product Inhibition by Glucose 1-phosphate
}

\author{
A. LANG, H. GROEBE, B. HELLKUHL, AND K. VON FIGURA ${ }^{(1 ;)}$ \\ Institute of Physiological Chemistry, University of Münster, Waldeyerstrasse 15, D 4400 Münster, \\ West Germany [A. L., K. V. F.]; Childrens Hospital, University of Münster, Robert-Koch-Strasse 31, D 4400 \\ Münster, West Germany [H. G.J; and Institute of Human Genetics, University of Münster. \\ Vesaliusweg 12-14, D 4400 Münster. \\ West Germany [B. H.]
}

\section{Summary}

In the erythrocytes of a patient with the clinical symptoms of galactosemia, a galactose-1-phosphate uridylyltransferase with abnormal kinetics was observed. Under standard assay conditions, the uridylyltransferase activity was almost normal initially and became completely inactivated within $30 \mathrm{~min}$. The abnormal kinetics could be ascribed to a product inhibition by glucose 1phosphate. The inhibition was produced by a variety of sugar phosphates, the most potent of which proved to be glucose 1 phosphate, mannose 1-phosphate, and fructose 6-phosphate. The variant galactose-1-phosphate uridylyltransferase was further characterized by a lowered affinity towards galactose 1-phosphate, non-Michaelis-Menten kinetics towards UDP-glucose, an increased thermal stability, and complete inactivity upon Cellogel electrophoresis.

\section{Speculation}

The erythrocyte galactose-1-phosphate uridylyltransferase of the patient was almost completely inhibited at $50 \mu \mathrm{M}$ glucose 1phosphate, which is within the range of the stationary glucose 1phosphate concentration reported for liver. These findings suggest that the product inhibition of galactose-1-phosphate uridylyltransferase by glucose 1-phosphate is responsible for the impaired galactose-1-phosphate metabolism in the patient.

Classical galactosemia is an autosomal recessive disorder of galactose metabolism characterized by vomiting, diarrhea, jaundice, failure to thrive, progressive mental and motoric retardation, and development of liver cirrhosis and cataracts (for review, see Ref. 12). The basic defect is the inactivity of galactose-1-phosphate uridylyltransferase (UDP-glucose: $\alpha$-D-galactose-1-phosphate uridylyltransferase, EC 2.7.7.12) (6), which will be referred to as transferase. The transferase deficiency galactosemia has to be distinguished from the galactokinase (EC 2.7.1.6) deficiency galactosemia, which is associated with less severe clinical symptoms (3).

Several variants of the transferase deficiency galactosemia have been reported. The "Negro" variant is characterized by milder expression of the clinical symptoms associated with the absence of transferase activity in erythrocytes and a residual activity of about $10 \%$ in liver and intestine (13). The "Rennes" and the "Indiana" variants exhibit the severe symptoms of galactosemia, but their residual activities of transferase in erythrocytes are $7 \%$ and up to $45 \%$, respectively (11). The electrophoretic mobility of both variant transferases is reduced, and the Indiana variant is additionally characterized by instability upon storage in heparin and phosphate buffer. The "Chicago" variant is characterized by mild clinical symptoms associated with $25 \%$ residual activity in erythrocytes and fibroblasts. This activity results from the combination of two mutant alleles of the transferase in a genetic compound (2).

The present study describes a new variant of galactosemia in which the transferase of erythrocytes becomes inactivated during incubation. This inactivation is likely to be caused by glucose 1phosphate, a product of the transferase reaction.

\section{CASE REPORT}

A detailed clinical description of the patient, his pedigree, and transferase activities determined with a UDP-glucose consumption test has been reported earlier by Matz et al. (9). Within the first two wk, the patient, G. R., now 4 years old, developed jaundice, vomiting, failure to thrive, hepatosplenomegalia, and opisthotonus. Under a galactose-free diet, the symptoms reversed, and the child has shown a normal development up to now.

\section{MATERIALS AND METHODS}

\section{MATERIALS}

$\left[U-{ }^{14} \mathrm{C}\right]$ Galactose-1-phosphate (specific activity, $348 \mathrm{mCi}$ / mmol) and $\left[U_{-}^{14} \mathrm{C}\right]$ glucose 1-phosphate (specific activity, 328 $\mathrm{mCi} / \mathrm{mmol}$ ) were obtained from Amersham-Buchler (Braunschweig). UDP-glucose dehydrogenase (EC 1.1.1.22) from bovine liver (specific activity, 0.6 units/mg protein), phosphoglucomutase (EC 2.7.5.1) from rabbit muscle (specific activity, 200 units/mg protein), glucose 6-phosphate dehydrogenase (EC 1.1.1.49) from yeast (specific activity, 140 units/mg protein), and 6-phosphogluconate dehydrogenase (EC 1.1.1.44) from yeast (specific activity, 12 units/mg protein) were purchased from Boehringer Mannheim (Mannheim). NADP and sugar phosphates, all sodium or potassium salts, were obtained from Boehringer Mannheim and Serva (Heidelberg), cellulose acetate gel (Cellogel) was obtained from Chemetron (Milano), DE52 cellulose was obtained from Whatman (Maidstone), and Dowex $1 \times 2,200$ to $400 \mathrm{mesh}, \mathrm{Cl}^{-}$-form was obtained from Serva.

\section{TRANSFERASE ASSAY}

Unless otherwise stated, the transferase activity was determined according to Bertoli and Segal (1) according to the modification of Shin-Bühring et al. (14). Heparinized venous blood was centrifuged, and the erythrocyte pellet was washed three times with 0.15 $\mathrm{M} \mathrm{NaCl}$ and finally suspended in distilled water to yield a hemoglobin concentration of about $70 \mathrm{mg} / \mathrm{ml}$. The hemolysate was frozen once and then incubated for $15 \mathrm{~min}$ at $37^{\circ} \mathrm{C}$ to destroy NAD. Transferase activity was assayed in $100 \mathrm{mM}$ glycine: $\mathrm{NaOH}$, pH 8.7 , containing $50 \mathrm{mM}$ cysteine: $\mathrm{HCl}, 2.95 \mathrm{mM}\left[U^{14}{ }^{14} \mathrm{C}\right]$ galac- 
tose 1-phosphate (specific activity, $0.254 \mathrm{mCi} / \mathrm{mmol}$ ), $1.2 \mathrm{mM}$ UDP-glucose, and $50 \mu \mathrm{l}$ hemolysate in a final volume of $100 \mu \mathrm{l}$. Blanks were incubated with hemolysate boiled for $5 \mathrm{~min}$

After incubation for $10 \mathrm{~min}$ at $37^{\circ} \mathrm{C}$, the mixture was boiled for $3 \mathrm{~min}$. After centrifugation, $50 \mu \mathrm{l}$ of the supernatant were loaded on a DE52 cellulose column $(0.5 \times 4 \mathrm{~cm})$ equilibrated with $20 \mathrm{mM}$ $\mathrm{HCl}$. $\left[U-{ }^{14} \mathrm{C}\right]$ Galactose-1-phosphate was eluted with $8 \mathrm{ml}$ of 20 $\mathrm{mM} \mathrm{HCl}$ and UDP- $\left[U-{ }^{14} \mathrm{C}\right]$ galactose with $5 \mathrm{ml}$ of $100 \mathrm{mM} \mathrm{HCl}$. The eluants were assayed for ${ }^{14} \mathrm{C}$-labeled radioactivity with three volumes of a scintillation medium made of $12 \mathrm{mM}$ PPO and 0.6 $\mathrm{mM}$ POPOP in a toluene:Triton X-100 mixture of 1:0.35 (v/v). The counting efficiency was 78 and $76 \%$ in the presence of 20 and $100 \mathrm{mM} \mathrm{HCl}$, respectively. Transferase activity was calculated as $\mu \mathrm{mol}$ UDP- $\left[U-{ }^{14} \mathrm{C}\right]$ galactose formed per $\mathrm{g}$ hemoglobin $(\mathrm{Hb})$ and $h$.

The coupling of the transferase reaction to glucose 1-phosphateconsuming reactions by inclusion of phosphoglucomutase and glucose 6-phosphate dehydrogenase was carried out according to Tedesco (15) and to Pesce et al. (10).

\section{ELECTROPHORESIS ON CELLOGEL}

Electrophoresis on Cellogel was modified from the starch gel electrophoresis described by Harris and Hopkinson (5). The separation was carried out at $200 \mathrm{~V}$ for $2 \mathrm{hr}$ at $4^{\circ} \mathrm{C}$ in $0.04 \mathrm{M}$ Trishistidine, $\mathrm{pH}$ 8.0. The staining mixture contained $9.84 \mathrm{mM} \mathrm{MgCl}_{2}$, $0.475 \mathrm{mM}$ NADP, $0.02 \mathrm{mM}$ glucose 1,6-diphosphate, $7.7 \mathrm{mM}$ galactose-1-phosphate, $3.5 \mathrm{mM}$ UDP-glucose, 8 units phosphoglucomutase, 2.8 units glucose 6-phosphate dehydrogenase, and 2.4 units 6-phosphogluconate dehydrogenase in a final volume of $2 \mathrm{ml}$ of $0.13 \mathrm{M}$ glycylglycine, $\mathrm{pH}$ 8.7. The gel was soaked with the staining mixture and incubated at $37^{\circ} \mathrm{C}$ for 1 to $2 \mathrm{hr}$. Transferase activity was visualized as fluorescence under longwave UV light.

\section{RESULTS}

The transferase activity in the hemolysate of the patient $G$. R. was $8.1 \mu \mathrm{mol} \times \mathrm{g} \mathrm{Hb}^{-1} \times \mathrm{h}^{-1}$ (mean of six independent determinations with a range of 5.9 to $\left.9.4 \mu \mathrm{mol} \times \mathrm{g} \mathrm{Hb}^{-1} \times \mathrm{h}^{-1}\right)$ corresponding to $33 \%$ of the activity of controls $(n=14)$. When the time course of UDP- $\left[U_{-}{ }^{14} \mathrm{C}\right]$ galactose formation was followed for up to $2 \mathrm{hr}$, it became evident that an initially high rate of uridylyl transfer rapidly decreased to zero within $30 \mathrm{~min}$ (Fig. 1). The product of the reaction was identified as $\left({ }^{14} \mathrm{C}\right]$ UDP-galactose as follows. The material eluted from DE52 cellulose with $100 \mathrm{mM}$
$\mathrm{HCl}$ was freeze-dried and applied, together with a UDP-galactose standard, onto a Dowex I x 2 column. The ${ }^{14} \mathrm{C}$-labeled transferase product and the UDP-galactose standard coeluted when a linear $\mathrm{NaCl}$ gradient made of $60 \mathrm{ml} \mathrm{H}_{2} \mathrm{O}$ and $60 \mathrm{ml} 0.5 \mathrm{M} \mathrm{NaCl}$ was applied to the column (not shown).

The rapid loss of uridylyl transfer during incubation suggested an increased lability of the enzyme during incubation or inhibition of the enzyme by one of its two products. Compared to controls the thermal stability of the variant transferase was even increased (Fig. 2). The transferase of patient G. R., however, was sensitive to inhibition by low concentrations of glucose 1-phosphate (Fig. 3 ), whereas the transferase activity of controls was not inhibited by up to $0.25 \mathrm{mM}$ glucose 1-phosphate. UDP-galactose had no inhibitory effect on the transferase activity of patient $G$. R. and controls (Fig. 4). A concentration of $40 \mu \mathrm{M}$ glucose 1-phosphate, which reduces the variant transferase activity to $50 \%$, is generated under standard assay conditions within less than $3 \mathrm{~min}$. Thus, the $50 \%$ reduction of transferase activity in patient G. $R$. determined after incubation for $5 \mathrm{~min}$ (Fig. 1) could well be explained as the result of product inhibition. The transferase activity of patient $G$. $R$. is reduced additionally, due to the lowered affinity of the variant enzyme towards galactose-1-phosphate. The $K_{M}$ for galactose-1-phosphate was repeatedly about 7 times higher than in controls (Fig. 5). Towards UDP-glucose, the patient's transferase showed a non-Michaelis-Menten kinetic whereas the $K_{M}$ for controls was $0.14 \mathrm{mM}$ (range of four determinations, 0.12 to 0.16 $\mathrm{mM})$. Affinities for glucose 1-phosphate and UDP-galactose could not be determined due to the inhibitory effect of glucose 1 phosphate.

The analysis of the conversion rate of $\left[U-{ }^{14} \mathrm{C}\right]$ glucose 1 -phosphate to UDP- $\left[U_{-}^{14} \mathrm{C}\right]$ glucose in the presence of low $\left[U-{ }^{14} \mathrm{C}\right] \mathrm{glu}-$ cose 1-phosphate (below $10 \mu \mathrm{M}$ ) and high UDP-galactose (2.95 $\mathrm{mM}$ ) concentrations revealed that under these conditions the rate of UDP- $\left[U-{ }^{14} \mathrm{C}\right]$ glucose formation by the hemolysate of patient $\mathrm{G}$. R. was $45 \%$ of that of a control (Table 1). In addition to glucose 1-phosphate, a variety of phosphorylated hexoses and pentoses were found to inhibit the transferase activity of patient G. R. (Table 2). None of these inhibitory sugar phosphates had an effect on the transferase activity of controls.

All attempts failed to prevent the glucose 1-phosphate-mediated inhibition of transferase by inclusion of phosphoglucomutase, glucose 6-phosphate dehydrogenase, and NADP under conditions as described by Tedesco (15) and Pesce et al. (10)

In the hemolysates of the parents, transferase activities reduced

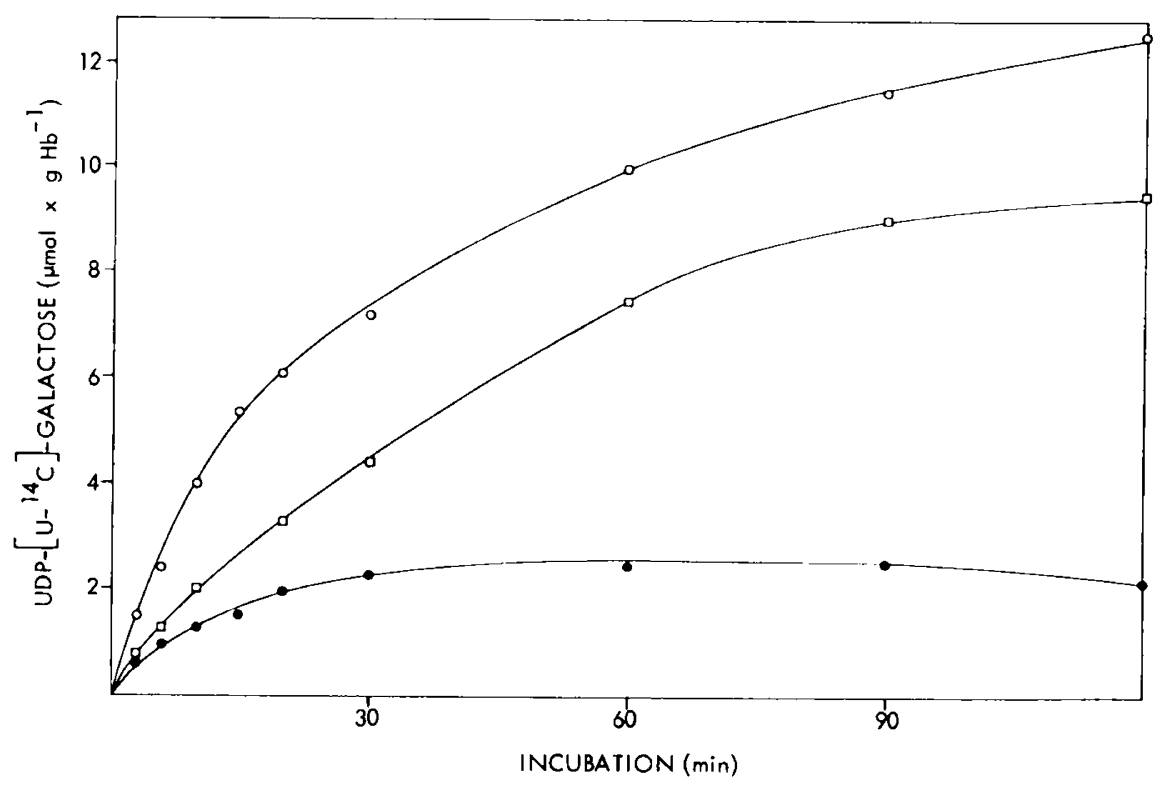

Fig. 1. Formation of UDP- $\left[U \cdot{ }^{14} \mathrm{C}\right]$ galactose by hemolysate of the patient $(\Theta)$, control $(\mathrm{O})$, and of the patient's mother $(\square)$ as function of incubation time. 


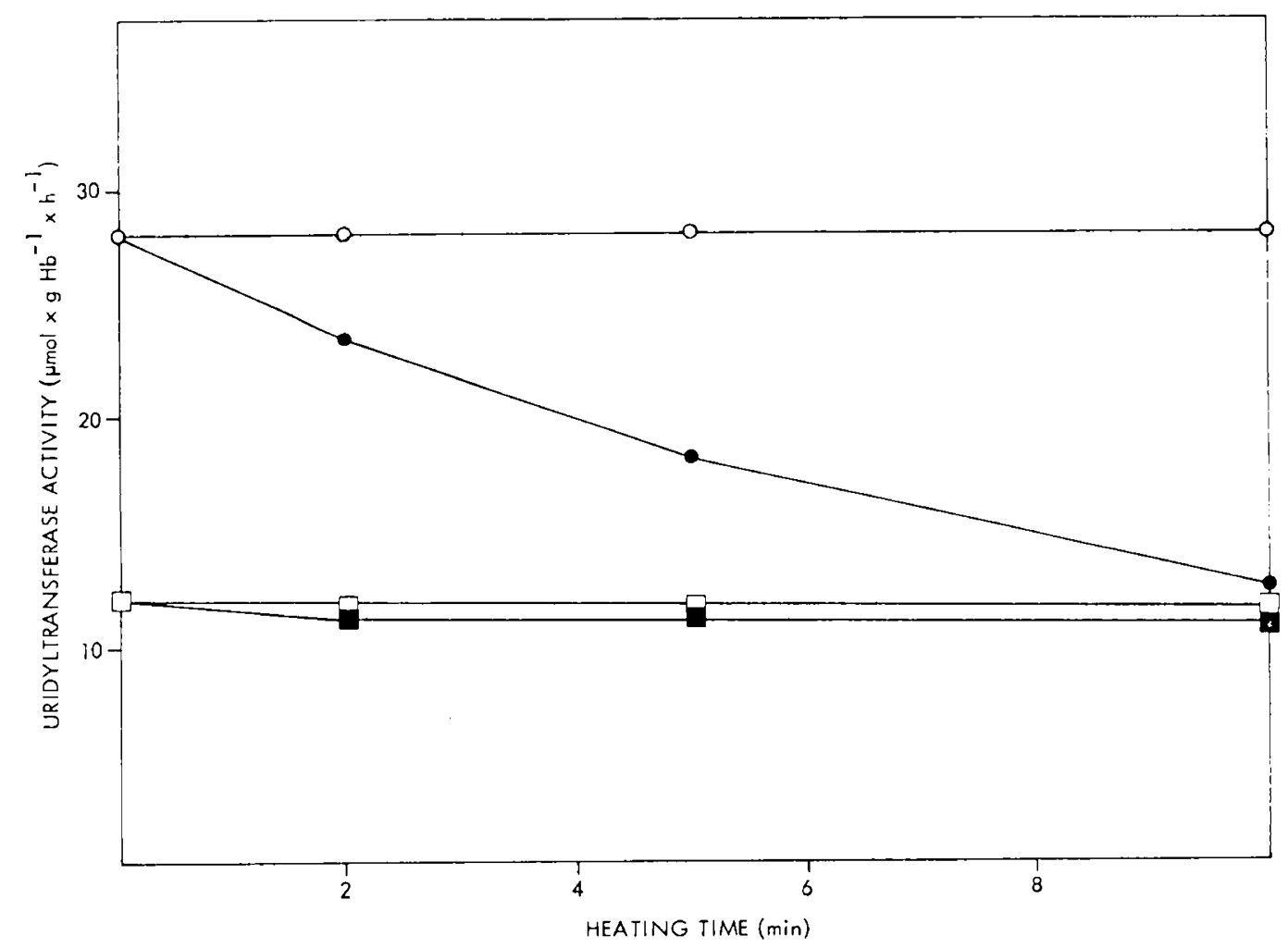

Fig. 2. Thermal stability of uridyltransferase activity of patient $G$. R. $(\square, \square)$ and controls $(O, \bullet)$. The hemolysates were kept for up to $10 \mathrm{~min}$ either at $40^{\circ} \mathrm{C}(\square, O)$ or at $50^{\circ} \mathrm{C}(\square, 0)$.

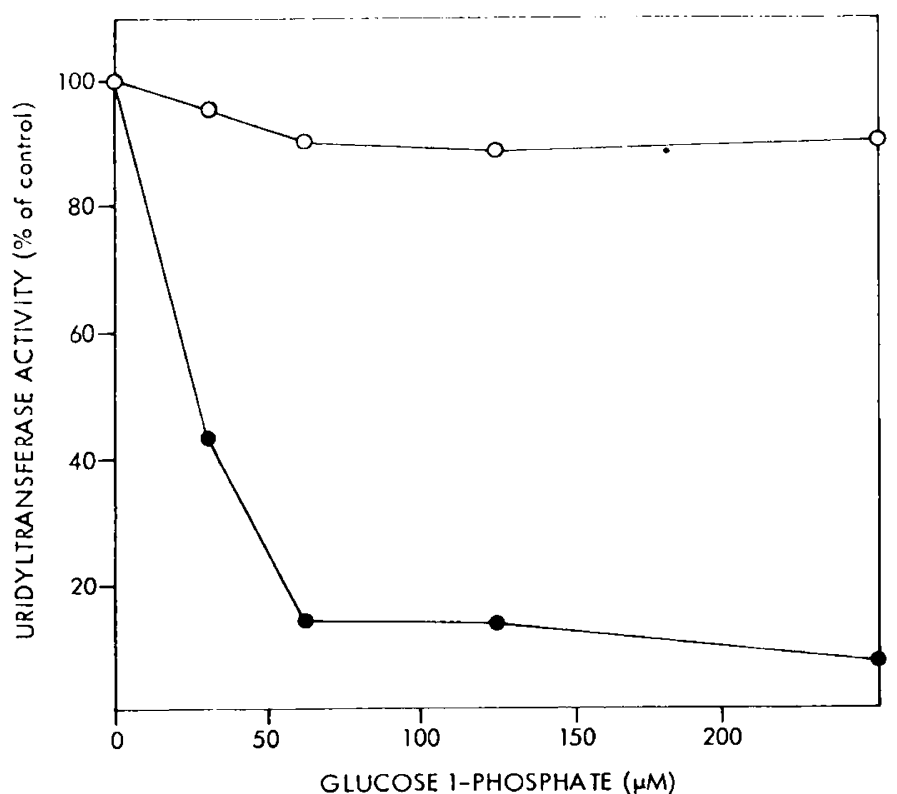

Fig. 3. Effect of glucose 1-phosphate on the uridyltransferase activity of patient G. R. (๑) and of control $(O)$. Activity is expressed as percentage of a glucose 1-phosphate-free control.

to 42 and $45 \%$ of that of controls were found. Of 18 relatives investigated, 8 had activities within the patient's parents range (Fig. 6). These results are similar to those previously obtained with an UDP-glucose consumption test (9). When the formation of UDP-[ $\left.U-{ }^{14} \mathrm{C}\right]$ galactose is followed over $120 \mathrm{~min}$, it becomes evident that during the first $20 \mathrm{~min}$ the apparent residual activity is relatively lower than after incubation for 60 to $120 \mathrm{~min}$ when product formation is impaired in controls by the consumption of up to $30 \%$ of the added substrates. Inclusion of $100 \mu \mathrm{M}$ glucose 1-

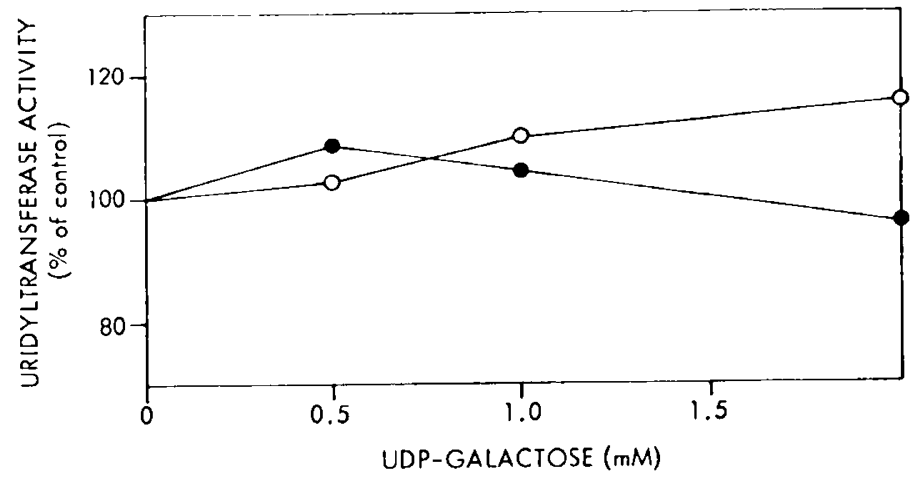

Fig. 4. Effect of UDP-galactose on the uridyltransferase activity of patient G. R. (๑) and of control $(O)$. Activity is expressed as percentage of a UDP-galactose-free control.

Table 1. UDP- $/ U_{-}^{14} \mathrm{C} /$ glucose formation in the presence of low $\left[U^{14}{ }^{14}\right.$ ]glucose concentration

\begin{tabular}{lcc}
\hline & $\begin{array}{c}{\left[U-{ }^{14} \mathrm{C}\right] \text { Glucose }} \\
1-\text { phosphate } \\
(\mu \mathrm{M})\end{array}$ & $\begin{array}{c}\left.\text { UDP-[U }-{ }^{14} \mathrm{C}\right] \text { glucose for- } \\
\text { mation }\left(\mathrm{nmol} \times 15 \mathrm{~min}^{1}\right. \\
\times \mathrm{g} \mathrm{Hb}\end{array}$ \\
\hline Patient G. R. & 1 & 7.6 \\
Control & 10 & 57 \\
& 1 & 16.1 \\
\hline
\end{tabular}

' Concentration of UDP-galactose was $2.95 \mathrm{mM}$ and incubation time $15 \mathrm{~min}$.

phosphate had a slight inhibitory effect on the transferase activity of both parents hemolysate similar to that in controls (inhibition by 18 to $20 \%$ in the parents and $10 \%$ in the controls). This indicates that the mutant uridyltransferase in the parents hemolysate contributes only little to the formation of UDP- $\left[U-{ }^{14} \mathrm{C}\right]$ galactose, 


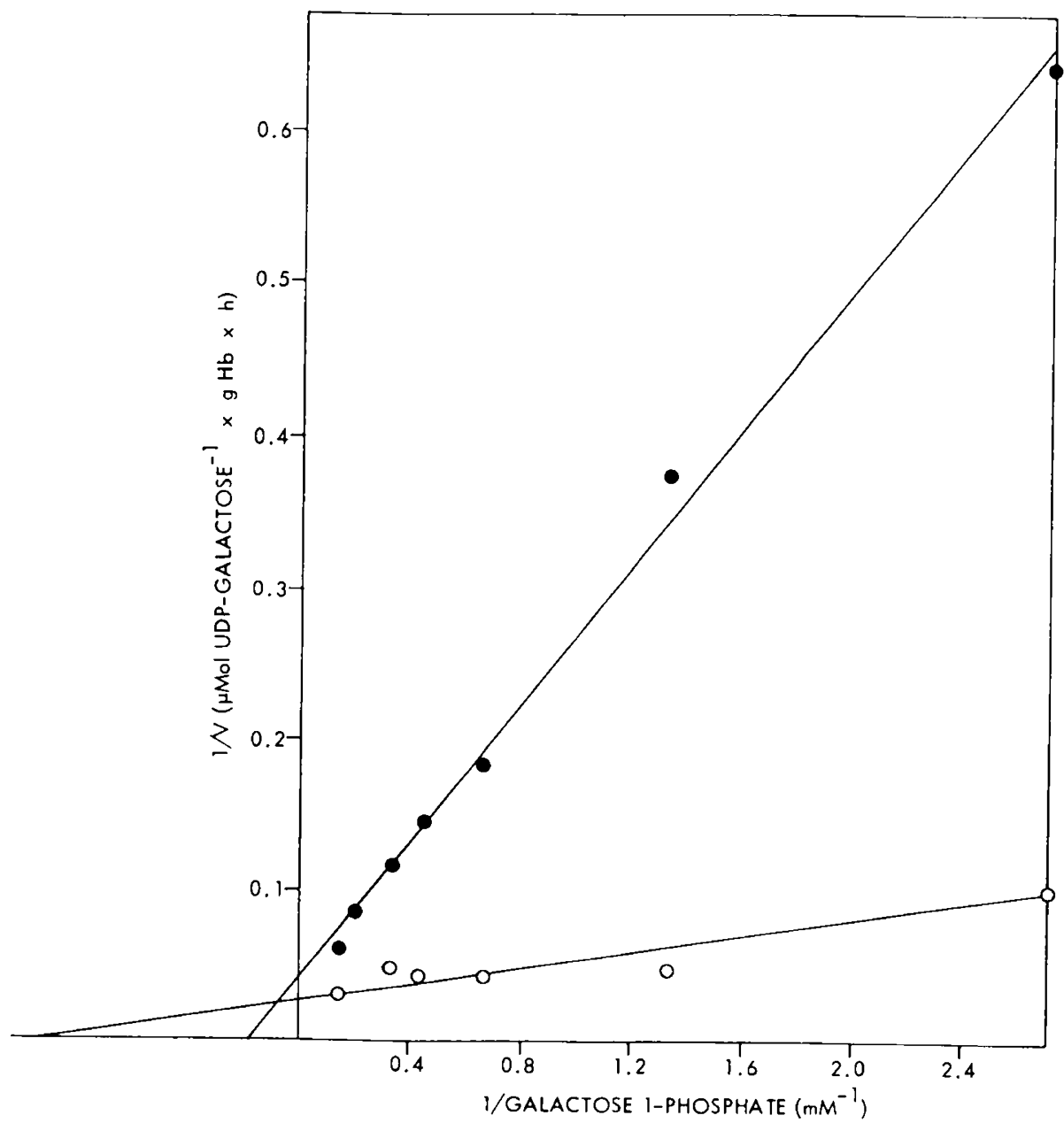

Fig. 5. Effect of galactose-1-phosphate on UDP-[U- $\left.{ }^{14} \mathrm{C}\right]$ galactose formation. The UDP-glucose concentration was $1.2 \mathrm{mM}$. The $\mathrm{K}_{\mathrm{M}}$ for galactose- 1 phosphate was $7.1 \mathrm{mM}$ for the patient G. R. (๑) and $1.02 \mathrm{mM}$ for control $(O)$.

Table 2. Inhibition of transferase activity of patient $G$. R. by glucose and sugar phosphates

\begin{tabular}{lcc}
\hline & \multicolumn{2}{c}{ Transferase activity } \\
\cline { 2 - 3 }$(0.25 \mathrm{mM})$ & $\left(\mu \mathrm{Mol} \times \mathrm{g} \mathrm{Hb}^{-1} \times\right.$ & \\
\hline None & 4.00 & 100 \\
Glucose 1-phosphate & 0.30 & 7 \\
Glucose 6-phosphate & 0.88 & 22 \\
Fructose 1-phosphate & 3.84 & 96 \\
Fructose 6-phosphate & 0.33 & 8 \\
Mannose 1-phosphate & 0.23 & 6 \\
Mannose 6-phosphate & 1.24 & 31 \\
Galactose-6-phosphate & 0.84 & 21 \\
Ribulose 5-phosphate & 2.40 & 60 \\
Glucose & 2.52 & 63 \\
$N$-Acetylglucosamine & 2.88 & 72 \\
\hline
\end{tabular}

${ }^{1}$ The activity of the control in the presence of these compounds was within 90 and $102 \%$ of that of a sugar phosphate-free control.

presumably due to the fact that inhibitory glucose 1-phosphate concentrations are reached more rapidly.

By electrophoresis on Cellogel, the obligate heterozygote parents revealed a normal mobility of the residual transferase activity. Attempts to detect transferase activity in the hemolysate of patient G. R. failed (Fig. 7), although a coupled reaction depleting glucose 1-phosphate was used.

\section{DISCUSSION}

The residual transferase activity in the hemolysate of patient $G$. R. who, within the first two wk after birth, developed the typical symptoms of galactosemia, was characterized by (1) inhibition by glucose 1-phosphate and several other sugar phosphates; (2) reduced affinity towards galactose-1-phosphate; (3) non-MichaelisMenten kinetics towards UDP-glucose; (4) increased thermal stability; and (5) inactivity upon electrophoresis on Cellogel.

The reduced transferase activity can be attributed in part to the 7 -fold increased $K_{M}$ towards galactose-1-phosphate. The almost complete inactivation of the enzyme within less than $30 \mathrm{~min}$ incubation, however, is probably due to the product inhibition by glucose 1-phosphate. It cannot be definitely answered whether the inhibition by glucose 1-phosphate as observed under in vitro conditions is responsible for the abnormal galactose metabolism in the patient. The stationary concentrations of glucose 1-phosphate in erythrocytes has been reported to be $500 \mu \mathrm{M}(4)$. This concentration is sufficient for complete inactivation of the patient's transferase. It is, however, unclear whether similar conditions are met in the liver, which is the main organ for galactose. If the liver transferase has the same characteristics as that of erythrocytes, a marked reduction of transferase activity will be produced by the stationary glucose 1-phosphate concentration in liver, which has been determined to be $60 \mu \mathrm{M}$ with the freeze-stop technique (7).

The transferase reaction seems to proceed in two half reactions (8).

enzyme + UDP-glucose $\rightleftharpoons$ UMP-enzyme + glucose 1-phosphate 


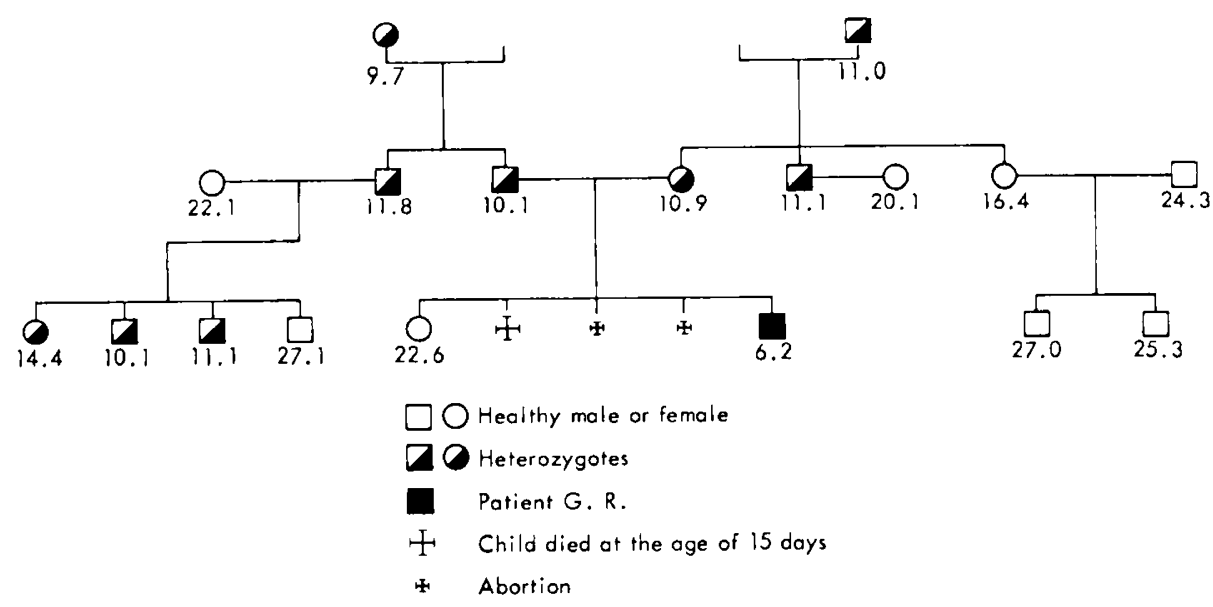

Fig. 6. Pedigree of patient G. R.'s family with the uridyltransferase activity $\left(\mu \mathrm{mol}\right.$ UDP- $\left[U-{ }^{14} \mathrm{C}\right.$ lgalactose $\times g \mathrm{Hb}^{-1} \times \mathrm{h}^{1}$.

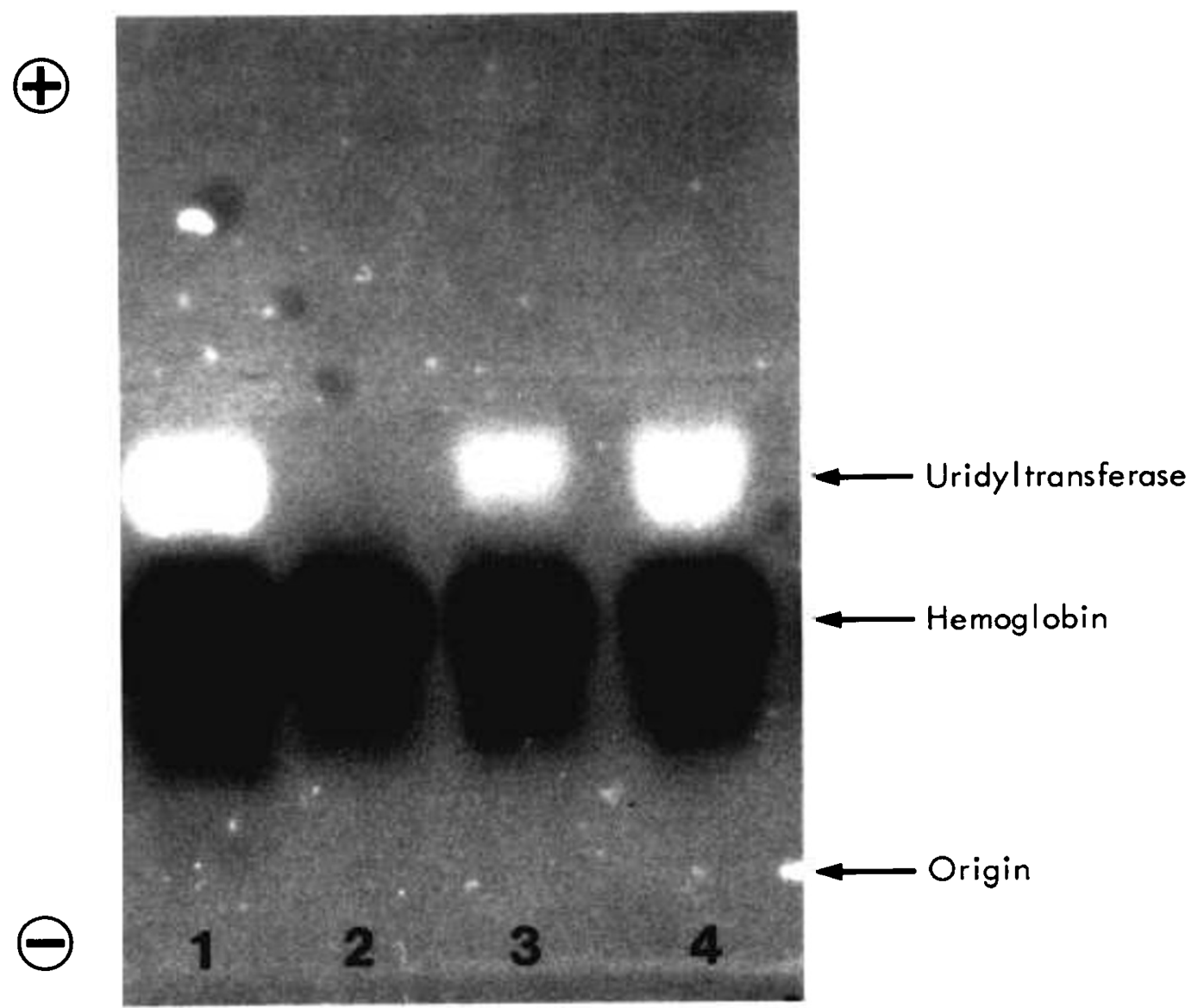

Fig. 7. Mobility of uridyltransferase of control (I), patient G. R. (2), father (3), and mother (4) on Cellogel.

\section{UMP-enzyme + galactose-1-phosphate $\rightleftharpoons$ enzyme + UDP-galactose}

The backward reaction could only be tested at very low glucose 1-phosphate concentrations. Under such conditions, the rate of UDP-glucose formation was somewhat less than $50 \%$ of that of a control. These results indicate that an exchange of glucose 1phosphate and glactose-1-phosphate at the sugar-binding site of the enzyme (8) is possible, but is inhibited in the presence of high glucose 1-phosphate concentrations. Glucose 1-phosphate might interfere with uridylyl transfer by blocking the interaction of the UDP-galactose and UDP-glucose with the enzyme. Inhibition of uridylyl transfer by glucose 1-phosphate concentrations is also known for normal transferase, but much higher glucose 1-phosphate concentrations are required. Thus, the transferase activity of adult rat liver is reduced to $50 \%$ in the presence of $0.8 \mathrm{mM}$ glucose 1-phosphate (1).

The product inhibition by glucose 1-phosphate could not be reversed by coupling the transferase reaction to glucose 1-phosphate-consuming reactions. This might indicate a high affinity of glucose 1-phosphate for transferase, exceeding that towards phosphoglucomutase and/or an inhibition produced by products generated by the phosphoglucomutase/glucose 6-phosphate dehydrogenase reactions, such as glucose 6-phosphate and 6-phosphogluconate. Suming up, the abnormal product inhibition by glucose 1 phosphate could well explain the development of galactosemia in 
the patient. The other abnormal characteristics, such as reduced affinity to galactose-1-phosphate and increased thermostability, seem to be of less significance for the impaired metabolism of galactose-1-phosphate in the patient.

\section{REFERENCES AND NOTES}

1. Bertoli, D., and Segal, S.: Developmental aspects and some characteristics of mammalian galactose 1-phosphate uridyltransferase. J. Biol. Chem., 24I: 4023 (1966).

2. Chacko. C. M., Wappner, R. S., Brandı. I. K., and Nadler, H. L.: The Chicago variant of clinical galactosemia. Humangenetik, 37: 261 (1977)

3. Gitzelmann. R.: Hereditary galactokinase deficiency, a newly recognized cause of juvenile cataracts. Pediatr. Res., 1: 14 (1967).

4. Gourly. D. R. H.: The role of adenosine triphosphate in the human erythrocyte. Arch. Biochem. Biophys., 40: (1952).

5. Harris, H.. and Hopkinson, D. A.: Handbook of Enzyme Electrophoresis in Human Genetics. (Oxford University Press. London, 1976).

6. Isselbacher, K., Anderson, E. P., Kurahashi, K., and Kalckar, H. M.: Congenital galactosemia, a single enzymatic block in galactose metabolism. Science, 123: 635 (1956).

7. Long, C.: Biochemist's Handbook. (Spon., London, 1961).

8. Markus, H. B., Wu, J. W., Boches, F. S., Tedesco, T. A., Mellness, W. J., and Kallen, R. G.: Human erythrocyte galactose 1-phosphate uridylyltransferase. J. Biol. Chem., 252: 8363 (1977).

Copyright $\odot 1980$ International Pediatric Research Foundation, Inc $0031-3998 / 80 / 1405-0729 \$ 02.00 / 0$
9. Matz, D., Enzenauer, J., and Menne, F.: Uber einen Fall von Atypischer Galaktosämie. Humangenetik. 27: 309 (1975).

10. Pesce, M. A., Bodourian, S. H., Harris, R. C., and Nicholson, J. F.: Enzymatic micromethod for measuring galactose 1 -phosphate uridyltransferase activity in human erythrocytes. Clin. Chem., 23: 1711 (1977).

11. Schapira. F.. and Kaplan, J. C.: Electrophoretic abnormality of galactose 1phosphate uridyl transferase in galactosemia. Biochem. Biophys. Res. Commun.. 35: 451 (1969).

12. Segal. S.: Disorders of galactose metabolism. In: J. B. Stanbury, J. B. Wyngaarden. D. S. Fredrickson: The Metablic Basis of Inherited Disease. pp. 160-181 (McGraw Hill Book Co.. New York, 1978)

13. Segal, S., Blair, A., and Topper. Y. J.: Oxidation of carbon-14 labeled galactose subjects with clinical galactosemia. Science, 136: 150 (1962).

14. Shin-Buhring. Y., Osang. M., Ziegler, R., and Schaub, J.: A method for galactose $\mathrm{I}$-phosphate uridyltransferase assay and the separation of its isoenzymes by 1-phosphate uridyltransferase assay and the separation of its isoenzymes by
DEAE-cellulose column chromatography. Clin. Chim. Acta., 70; 371 (1976)

15. Tedesco. T. A.: Human galactose 1-phosphate uridyltransferase. J. Biol. Chem. 247: 6631 (1972).

16. The authors thank M. Grüneberg and V. Sablitzky for their help.

17. Requests for reprints should be addressed to: K. von Figura. Institute of Physiological Chemistry. University of Muenster. Waldeyerstrasse 15, 4400 Muenster. West Germany.

18. This research was supported by the Deutsche Forschungsgemeinschaft (SFB 104)

19. Received for publication February 27, 1979.

20. Accepted for publication July 12. 1979. 